was not seen in model 2 (OR $=1.00$, 95\% CI 0.99-1.02). Work performance: increased work performance (presenteeism) was associated with a higher quality of life in both models (B coefficient $0.13,95 \% \mathrm{CI} 0.08-0.18$ and 0.12 , 95\% CI $0.05-$ 0.19 in models 1 and 2 respectively).

Conclusions The association between presenteeism and HRQoL has not previously been assessed in a UK COPD working population. Our findings show that after adjusting for all relevant confounders, employment status is not associated with quality of life. However, for those at work, a better quality of life is associated better work performance.

\section{P22 THE RELATIONSHIP BETWEEN SOCIAL DEPRIVATION AND HOSPITAL ADMISSIONS WITH ACUTE EXACERBATION OF CHRONIC OBSTRUCTIVE PULMONARY DISEASE (AECOPD)}

RJ Grecian, SM Grecian, J Wright, H Balata, A Ashish, I Aziz; Royal Albert Edward Infirmary, Wigan, United Kingdom

\subsection{6/thoraxjnl-2013-204457.172}

Background AECOPD is a major source of hospital admissions. Research is underway to reduce such admissions, but the effect of social deprivation on AECOPD hospital admissions and length of stay is unknown.

Aims and Objectives To analyse the effect of social deprivation on hospital admissions and length of stay in AECOPD.

Methods Retrospective review of hospitalisation with a primary diagnosis of AECOPD Sep 11-Aug 12 in a UK hospital. Patients were assigned an index of multiple deprivation score based on postcode and subdivided into quintiles. For each quintile, total admissions and median length of stay per admission were calculated and corrected for population size (per 100,000 residents). Fisher's exact test (two-tailed) was used to compare quintiles. The least deprived quintile represented $<5 \%$ of the population and was excluded.

Results There were significantly higher numbers of hospital admissions in patients from more deprived postcodes as compared to affluent areas $(\mathrm{p}<0.001)$. There was no significant difference in median length of stay between quintiles (Table 1).

Conclusions Patients from socio-economically deprived backgrounds have higher rates of hospital admissions with AECOPD. Deprivation does not influence length of stay; this could be due to a dedicated COPD unit. Increasing healthcare investment in deprived areas should be considered.

\begin{tabular}{|c|c|c|c|c|c|}
\hline \multicolumn{6}{|c|}{ COPD admissions and length of stay } \\
\hline Quintile & $\begin{array}{l}\text { Total } \\
\text { population }\end{array}$ & $\begin{array}{l}\text { COPD } \\
\text { admissions }\end{array}$ & $\begin{array}{l}\text { Admissions } \\
\text { per } 100 \mathrm{~K}\end{array}$ & $p$ value & $\begin{array}{l}\text { Median length } \\
\text { of stay } \\
\text { (interquartile } \\
\text { range) }\end{array}$ \\
\hline $\begin{array}{l}1 \\
\text { (most } \\
\text { deprived) }\end{array}$ & 98,560 & 442 & 448 & $\begin{array}{l}1 \text { vs. } 2-4 \\
p<0.0001\end{array}$ & $1(0-5)$ \\
\hline 2 & 70,840 & 244 & 344 & $\begin{array}{l}2 \text { vs. } 3-4 \\
p<0.001\end{array}$ & $2(0-6)$ \\
\hline 3 & 61,600 & 97 & 157 & $\begin{array}{l}3 \text { vs. } 4 \\
p=\text { not } \\
\text { significant }\end{array}$ & $2(0-5)$ \\
\hline 4 & 61,600 & 73 & 119 & $\mathrm{~N} / \mathrm{A}$ & $2(1-5)$ \\
\hline
\end{tabular}

P23 THE INCIDENCE OF CONGENITAL THORACIC
MALFORMATIONS: AN INCREASING TREND FROM 1994
TO 2011 IN A DEFINED POPULATION

${ }^{1}$ EA Gorman, ${ }^{1} S$ Thavagnanam, ${ }^{1} \mathrm{~J}$ Houton, ${ }^{2} \mathrm{~A}$ Dick, ${ }^{2} \mathrm{~A}$ Patterson, ${ }^{1} \mathrm{MD}$ Shields; ${ }^{1}$ Queen's University, Belfast, Northern Ireland; ${ }^{2}$ Royal Belfast Hospital for Sick Children, Belfast, Northern Ireland

\subsection{6/thoraxjnl-2013-204457.173}

Introduction Congenital thoracic malformations (CTMs) are an uncommon heterogenous group of disorders including congenital cystic adenomatous malformation (CCAM), pulmonary sequestration (PS), congenital lobar overinflation (CLO), hybrid lesions and bronchogenic cysts. They are increasingly diagnosed antenatally with foetal ultrasonography and remain asymptomatic. In light of diagnostic advances, robust population based epidemiology is lacking. This study aimed to characterise the incidence of CTMs in a defined geographic area from 1994 to 2011.

Methods Children with CTM in Northern Ireland are referred to a single tertiary centre. Patients with CTM born between 1994 and 2011 were identified from the paediatric respiratory and surgical clinics and from imaging reports on the regional radiology database. Medical records and imaging reports were reviewed retrospectively. Children diagnosed with CTM who were born outside of Northern Ireland were excluded.

All births in Northern Ireland are registered with the Registrar General Office. Annual live birth rates were obtained from the Northern Ireland Statistics and Research Agency. Incidence was calculated per 10000 live births.

Results In total there were 92 cases of CTM between 1994 and 2011, 53 cases (57\%) had CCAM. An upward trend in the incidence of CTMs is demonstrated (Figure 1). The average incidence of CTMs from 1994 to 1999, 2000 to 2005 and 2006 to 2011 was 0.49 (range 0.41 to 0.82 ), 1.6 (range 0.89 to 1.85 ) 4.08 (range 2.34 to 7.73 ) respectively. A similar increase in the incidence of CCAM was demonstrated 0.14 (range 0to 0.42), 1.22 (range 0.93 to 1.40 ) and 2.19 (range 0.39 to 5.59 ) for the periods 1994 to 1999, 2000 to 2005 and 2006 to 2011 respectively.

Conclusion This study provides incidence statistics for CTMs in a defined geographic location and demonstrates an

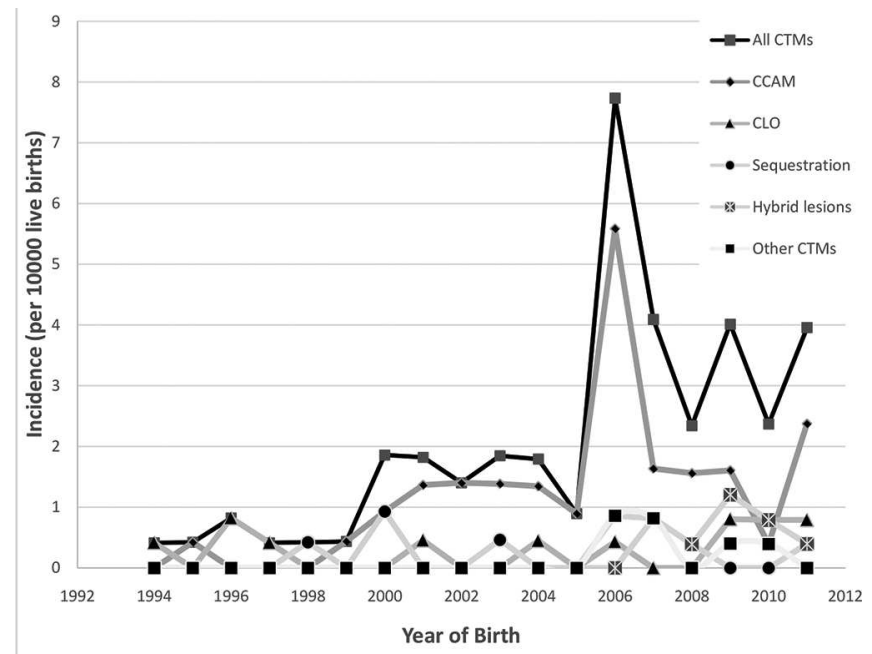

Abstract P23 Figure 1. Annual incidence of Congenital Thoracic Malformations between 1994 and 2011. 
increasing incidence between 1994 and 2011, likely due to advances in antenatal diagnosis. The retrospective nature of this study means that patients with CTM who were not followed up postnatally and not imaged postnatally would not be included. The incidence provided therefore represents the minimum incidence. The increasing incidence of CTMs has therapeutic implications as the complication rates may be lower than previously repoted.

\section{TB: Diagnosis and Management}

\section{P24 DIAGNOSING TUBERCULOSIS USING EBUS-CYTOLOGY IS NOT ENOUGH}

${ }^{1}$ RAM Breen, ${ }^{1} \mathrm{E}$ McLean, ${ }^{2} \mathrm{MCl}$ Lipman, ${ }^{1} \mathrm{G}$ Santis; ${ }^{1}$ Guys and St Thomas' NHS Foundation Trust, London, United Kingdom; ${ }^{2}$ Royal Free NHS Foundation Trust, London, United Kingdom

\subsection{6/thoraxjnl-2013-204457.174}

Introduction Endobronchial ultrasound with transbronchial needle aspiration (EBUS-TBNA) provides a technique for safely sampling mediastinal and hilar lymph nodes. In the diagnosis of tuberculosis (TB) published data has shown excellent performance in identifying suggestive cytology but with disappointing culture-confirmation rates of $<50 \%$. We sought to investigate the proportion of TB cases referred to our tertiary referral service in whom culture and sensitivities were obtained.

Methods EBUS-TBNA was performed by 2 experienced consultants with on-site cytology review. Data was abstracted from our prospective database of all EBUS-TBNA cases between 01/2008 and 01/2013, our hospital electronic record and by contacting referring clinicians. A final diagnosis of active TB was made if treatment for active TB was commenced subsequent to EBUSTBNA. Treated TB was defined as anyone who had received at least 2 months of anti-TB treatment prior to EBUS-TBNA.

Results A final diagnosis of active or treated $\mathrm{TB}$ was made in 142 of 2121 EBUS-TBNA cases (6.7\%). Sampled nodes were: right para-tracheal 32\%, left para-tracheal $9 \%$, right hilar $16 \%$, left hilar $8 \%$, sub-carinal 35\%. A median of 7 passes (range: 414) were performed per case. Granulomas with and without necrosis were identified in $91.5 \%$, necrosis alone in $4.9 \%$ and lymphocytes alone in $3.5 \%$. Of $118(73 \%)$ diagnosed with active $\mathrm{TB}$, culture-confirmation was obtained in 89 (75\%) with a median time to positive liquid culture of 27 days (range: 4-42). Cytology from cases of treated TB and active TB with and without culture-confirmation are compared in the Table.

Discussion These data suggest that EBUS-TBNA can obtain higher proportions of culture-confirmed TB than has been previously reported. The similar cytology profile seen in active TB cases regardless of smear status, culture result or treatment history highlights the need for both adequate samples to be sent for culture and for improved TB diagnostics.

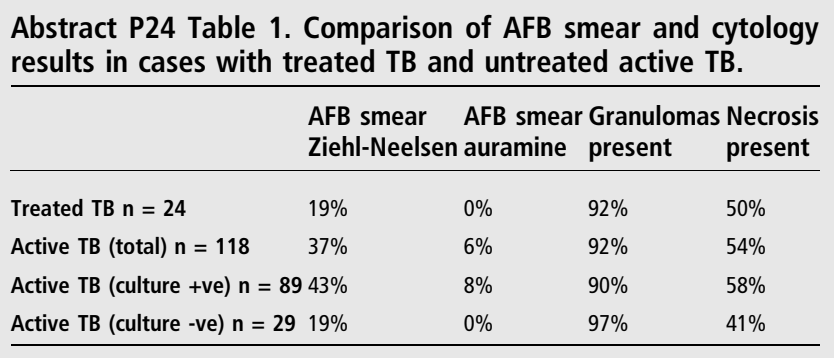

SENSITIVITY OF THE XPERT ${ }^{\circledR}$ MTB/RIF ASSAY IN BRONCHOALVEOLAR LAVAGE SAMPLES IN A NORTH WEST LONDON HOSPITAL: A USEFUL ADJUNCT TO CURRENT DIAGNOSTIC MODALITIES

CL Ross, M Anwar, M Wickremasinghe, G Cooke, M Rebec, E Fahy, A Jepson, OM Kon; Imperial College Healthcare NHS Trust, London, UK

10.1136/thoraxjnl-2013-204457.175

Introduction and Objectives The Gene Xpert ${ }^{\circledR}$ MTB/RIF test has been validated in sputum samples, facilitating rapid mycobacterium tuberculosis (MTB) diagnosis with improved sensitivity compared to smear alone. Its utility in bronchoalveolar lavage (BAL) samples, in a low prevalence setting, is unclear. Our objective was to examine the sensitivity of the Xpert ${ }^{\circledR}$ test in BAL samples and evaluate its use as a rapid diagnostic test in non-productive or smear negative patients undergoing bronchoscopy.

Methods We conducted a retrospective analysis of all cultureproven MTB samples acquired by BAL between 01.08.2009 and 01.06.2013, which were also sent for the Xpert ${ }^{\circledR}$ test, $n=38$. We assessed the proportion of Xpert ${ }^{\circledR}$ MTB positive samples and compared these results with smear status and time to culture positivity.

Results 26/38 of the culture-proven cases sent for analysis were MTB Xpert ${ }^{\circledR}$ positive, giving a sensitivity (if culture is taken as the 'gold standard') of $68 \%$. $17 / 38$ samples were smear positive. Of the 21 smear negative/culture positive samples, 43\% were MTB Xpert ${ }^{\circledR}$ positive. All smear positive cases were Xpert ${ }^{\circledR}$ positive. The Xpert ${ }^{\circledR}$ positive samples had a lower mean time to positivity: 11.2 days vs. 17.2 days for $\mathrm{Xpert}^{\circledR}$ negative samples. There was one case of rifampicin resistance correctly identified by Gene Xpert ${ }^{\circledR}$, giving a lead time of 28 days vs. culture sensitivity. Incidentally 4 additional Xpert ${ }^{\circledR}$ positive samples were identified which were BAL culture negative, all in patients with clinically likely MTB, one of whom went on to culture MTB from sputum, and one of whom had necrotising granulomas on subsequent endobronchial ultrasound-guided transbronchial needle aspiration.

Conclusions To our knowledge this is the largest series reported of MTB culture positive BAL samples analysed using the Xpert ${ }^{\circledR}$ MTB/RIF assay. This data supports the use of Xpert ${ }^{\circledR}$ in the diagnosis of pulmonary MTB in BAL fluid, with a sensitivity of $68 \%$ when compared to MTB culture, adding additional value to simple smear and early detection of rifampicin resistance. In fact, the true sensitivity may well be higher given the cases detected exclusively by Xpert $\AA$.

\section{P26 UTILITY OF THE CHEST X-RAY IN THE ERA OF IGRA TESTING FOR LATENT TB PRIOR TO ANTI-TNF THERAPY}

S Tsim, J Anwar, L McLure, G Roditi, MM Cotton; Glasgow Royal Infirmary, Glasgow, United Kingdom

\subsection{6/thoraxjnl-2013-204457.176}

Introduction Anti-TNF therapies are associated with increased risk of reactivation of latent Mycobacterium tuberculosis infection (LTBI). Screening for LTBI is recommended prior to commencing anti-TNF therapy. BTS guidelines for screening incorporate epidemiologic risk, clinical examination, Mantoux testing and chest radiography (CXR). Other guidelines recommend use of interferon gamma release assays (IGRAs). We audited the use of IGRA and CXR as part of screening for LTBI in 